\title{
A Method for Titrating Oxygen-Sensitive Organic Redox Systems with Reducing Agents in Solution ${ }^{1}$
}

\author{
B. D. BURleigh, JR., ${ }^{2}$ G. P. FOUST, ${ }^{3}$ and C. H. WILliams, Jr. \\ The Veterans Administration Hospital, and the Department of Biological Chemistry, \\ The University of Michigan, Ann Arbor, Michigan 48105
}

Received June 14, 1968

A long-term need has existed in the study of complex redox systems, such as the electron-transferring enzymes found in biological systems, for an accurate method of titrating a system through its various oxidation states using small increments of a reducing agent in solution (1). The methods to be described in this and the accompanying paper (2) were developed concurrently to perform this task. The method to be described in this paper makes adequate provision for flushing and exclusion of molecular oxygen, for addition of accurately measured increments of a standardized reducing agent, and for spectrophotometric observation of the solution being titrated. The general method, however, might easily be adapted for electrochemical measurements, paramagnetic resonance spectroscopy, or some other method of observation.

\section{OUTIJNE OF THE METHOD}

The method involves the use of a special cuvet unit, described below, which may alternately be evacuated and flushed with oxygen-free helium by attachment to a gas line and aspirator vacuum line. After the system under study (in its oxidized state because of the presence of oxygen) is placed in the cuvet and purged of all free molecular oxygen by the evacuation and flushing procedure, increments of the titrating solution are delivered from a Hamilton Gas-tite syringe, modified as described and fitted with a screw-thread plunger so that small increments of the titrant may be delivered with micrometer-like precision. The needle of the syringe passes into the oxygen-free cuvet through a rubber septum. The septum is fitted tightly into a specially made socket opening in the cuvet. An essential feature of the instrument is the use of

${ }^{1}$ This research was supported in part by Grant AM 09313 from the U. S. Public Health Service.

${ }^{2}$ National Science Foundation graduate trainee.

${ }^{3}$ National Institutes of Health prcdoctoral fellow. 
a gas-flow lock, described below, which places the septum in an oxygenfree environment on its outside surface, thus preventing possible diffusion of oxygen into the cuvet past the rubber septum.

\section{INSTRUMENTATION AND DETAIIS OF THE PROCEDURE}

The instrumentation of the method has the advantage of being relatively simple and inexpensive to construct and use. The curct unit, shown in Figure 1, was designed to fit directly into the cuvet holder of a Cary model 14 spectrophotometer, the instrument used for the observations in this study. The flask in which the titrant is prepared and from which the syringe is filled is shown in Figure 2. The arrangement by which these units are connected to the gas line and vacuum lines is shown in Figure 3. Figure 4 shows the arrangement of the various components on the bench in preparation for an experiment.

In this study the oxygen-sensitive compound, lumiflavin acetic acid, is titrated from its oxidized state, which is the stable state in the presence of oxygen, to its fully reduced state, using sodium dithionite solution as the reducing agent. The titration was followed spectrophotometrically at $443 \mathrm{~nm}$, one of the absorption maxima of the oxidized lumiflavin acetic acid. This titration fumishes a good test of the effectiveness of the flushing procedure and possible oxygen leaks because of the high velocity with which the reduced lumiflavin reacts with oxygen.

The working procedure used to make the measurements reported in this study is as follows:

(1) A small helium flow is maintained through the gas locks of the cuvet unit and the titrant flask during the preparation of the solutions and purging them of gas.

(2) The dithionite solution is prepared in the titrant flask. In a typical experiment $90 \mathrm{ml}$ of $0.1 M$ pyrophosphate buffer, $\mathrm{pH} 9.0$ (anjusted with $\mathrm{HCl}$ ), is placed in the flask (Fig. 2) with the rubber septum and gas lock fitted, the $7 / 25$ standard taper male joint on the gas lock being closed with a female cap. The ground-glass joints are all greased before fitting with Apiezon $N$ stopcoek grease. A magnetic stirring har is placed in the flask and the flask is then clamped above a magnetic stirring motor. The 19/22 standard taper female joint at the top of the flask is then fitted with the male joint and stopcock, which are connected as shown in Figures 3 and 4, to the racuum line and gas line via butyl rubber tubing and a 2-way stopcock. Helium flow is then started in the gas lock of the flask, and a vacuum from the water aspirator is applied alternately with oxygen-free helium by means of the 2-way stopcock. The solution is stirred continuously at this time with the magnetic stirrer. After 6 such purging cycles, the stirrer is turned off and 


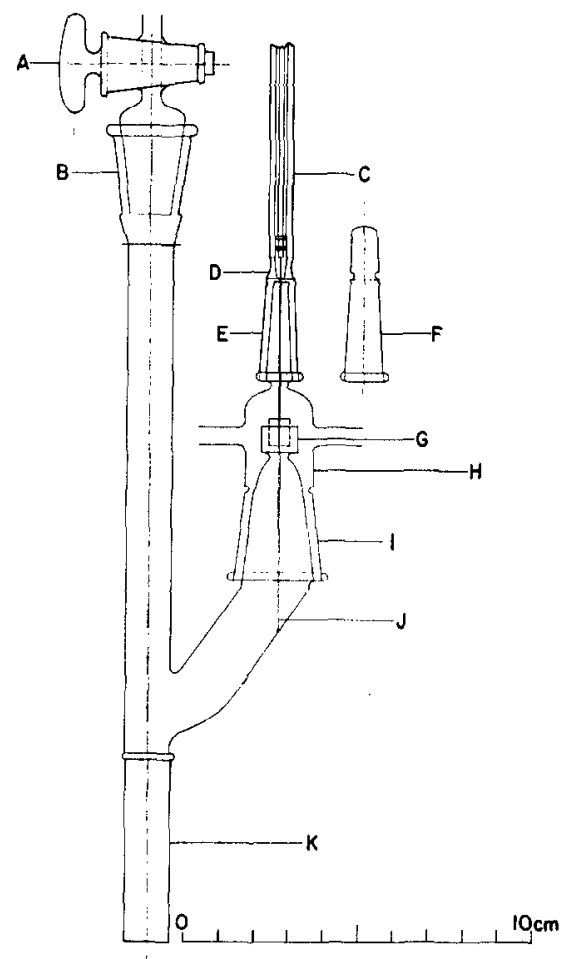

Fra. 1. Cuvet unit: (A) High-vacuum stopcock (Eck \& Krebs, Inc., Long Island City, New York, \#5000), jointed to $19 / 22$ standard taper male joint and 18/9 standard hemispherical socket joint (not shown). (B) 19/22 standard taper female joint. (C) IIamilton Gas-Tite syringe (\#87001), $0.5 \mathrm{ml}$, fitted with 4 in. needle and a screw-thread plunger unit. The luer taper at the end of the syringe barrel has been cemented with epoxy cement (Sears and Roebuck) to the female 7/25 standard taper joint (E). (F) A female 7/25 standard taper joint closed off with a tube end to form a cap. (G) A socket (Quality Glass Apparatus, Inc., 2821 S. State St., Ann Arbor, Mich.) for receiving a rubber gas chromatography septum, attached as shown to the 19/22 male joint of the cuvet unit, and through which the needle of the syringe (J) passes. (H) The gas-lock filting, through which oxygenfree gas passes via an inlet and exit tube as shown. The fitting ends in a female 19/22 standard taper joint and a male 7/25 standard taper joint for attachment to the cuvet unit and the syringe or cap, respectively. (K) Cuvet with graded seal to remainder of the cuvet unit. The cuvet may be made of glass or quartz depending on the wavelength of the absorbance to be followed. In these experiments, a Beckman glass cuvet was used since it was sufficient for the wavelengths employed.

the flask opened. The required amount of dithionite (or other reducing agent) is then added as the solid and allowed to sink to the bottom without stirring; the flask is quickly olosed again and 3 cycles of vacuum and gas purging applied with the stirrer remaining off. Typically $24 \mathrm{mg}$ 


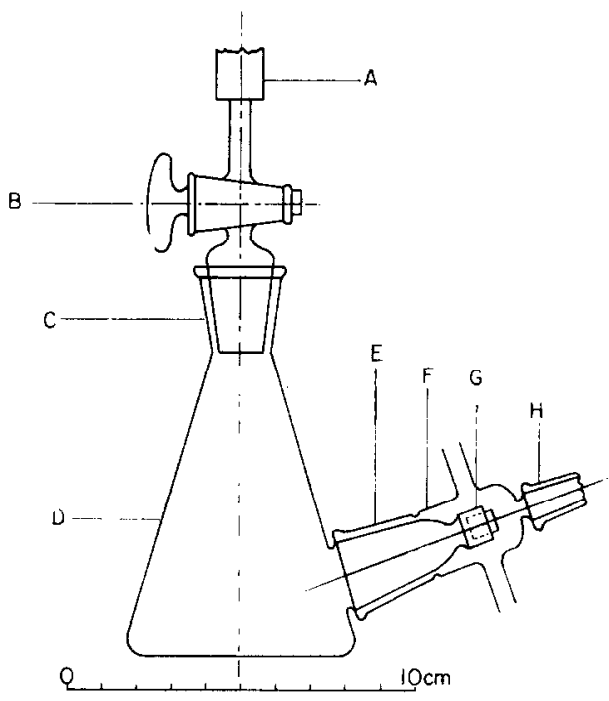

FIg. 2. The flask: (A) Butyl rubber tubing (Sargent \#S-73658, 1/4 in. i.d., 1/8 in. wall thickness) connecting the stopcock (B) joined to the male $19 / 22$ standard taper joint, to an $18 / 9$ standard ball joint which attaches the unit to the gas line and aspirator vacuum. (C) 19/22 female standard taper joint joined to the top of a $125 \mathrm{ml}$ Erlenmeyer Pyrex flask (D). (E, F, G, H) Parts of the gas-lock unit, which is identical to that described for the cuvet unit in Figure 1.

of sodium dithionite is added to make the solution about $1.5 \mathrm{mM}$ if the dithionite were $100 \%$ pure.

(3) The solution to be titrated is prepared in the cuvet; the cuvet is attached to the gas line and aspiralor vacuum, and then purged of oxygen by a procedure like that used with the flask, using 6 cycles of alternating gas and vacuum. Degassing of the cuvet is assisted by shaking while under vacuum, keeping the solution cold by immersion in ice water to prevent evaporation as much as possible. It is advantageous to take a spectral observation before and after the degassing procedure so that volume losses due to evaporation may be taken into account. As shown in Figure 3, the cuvet unit is attached to the 2-way gasvacuum stopcock using 18/9 standard hemispherical sockets and matching brass ball joints silver-soldered to a coil of $1 / 4$ in. copper tubing. This arrangement gives the flexibility necessary for agitation of the cuvet while degassing and maintains good exclusion of oxygen. However, care must be taken during this operation that the ball-and-socket joints are not disturbed after being greased and set up, as gas leaks are easily introduced in this manner. In a typical lumiflavin acetic acid titration, the cuvet contained the following: 
$0.30 \mathrm{ml}$ approx. $1.5 \mathrm{~m} M$ lumiflavin acetic acid

$1.00 \mathrm{ml} 0.1 \mathrm{M}$ pyrophosphate, $\mathrm{pH} 9.0$

$1.70 \mathrm{ml}$ glass-distilled water

$3.00 \mathrm{ml}$ total volume

(4) The syringe used in this study is a Hamilton Gas-tite $0.5 \mathrm{ml}$ type which is fitted with a 4 in. needle and a screw-thread plunger. The luer taper at the end of the barrel is cemented into a $7 / \mathbf{2 5}$

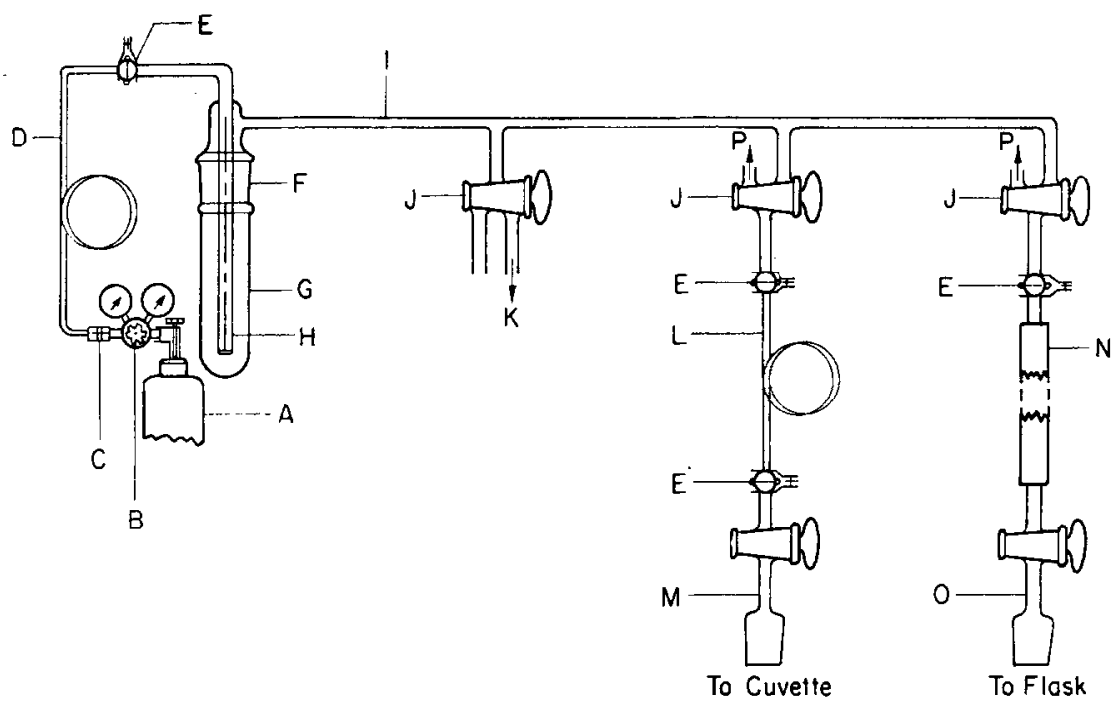

FIG. 3. Connections to gas and vacuum lines: (A) Low-oxygen special analysis helium (Airco Industrial Gases, Riverton, N. J., grade $6 \mathrm{He}$, cylinder, typical anal. $<0.1$ ppm $\mathrm{O}_{2}$ ). (B) High-quality regulator with low leak rate (Matheson High Purity Regulator, model 3500, with CGA connection 590). (C) Flare nut fitting. (D) $1 / 4$ in. copper tubing with coil of 3 turns as shown to give flexibility, silversoldered to $18 / 9$ standard brass ball joint. (E) $18 / 9$ glass socket joint fitted to brass ball joint with pressure clamp. (F) $34 / 45$ standard taper joint with tube (G) attached to female part. Joint is held together with ears and springs. (H) Fritterl glass fitting (Ace Glass, catalog \#7202, $10 \mathrm{~mm}$ diam.) which serves as bubbler; the tube is filled partly with water so that helium entering the gas line is water saturated. (I) Gas line, $16 \mathrm{~mm}$ o.d. Pyrex tubing. (J) Two-way stopcock, high vacuum individually fitted (Eck \& Krebs \#5020). (K) Gas outlet for gas locks of the cuvet unit and the flask unit. (L) $1 / 4$ in. copper tubing with coil of 3 turns to give flexibility, silver-soldered to two $18 / 9$ standard brass ball ends as shown for attachment to cuvet unit and gas-vacuum stopcock. (M) High-vacuum stopcock (Eck \& Krebs \# 5000) joined to $18 / 9$ glass socket and $19 / 22$ male standard taper joint, for attachment to cuvet unit. (N) Butyl rubber tubing (Sargent \#S-73658, $1 / 4$ in. i.d., $1 / 8$ in. wall thickness). (O) High-vacuum stopcock (Eck \& Krebs \#5000) attached to $19 / 22$ male standard taper joint for attachment to flask unit. (P) Outlets attached with butyl rubber tubing (Sargent \#S-73658, 1/4 in. i.d., 1/8 in. wall thickness) to individual aspirator vacuum pumps (Nalgene \#6140). 


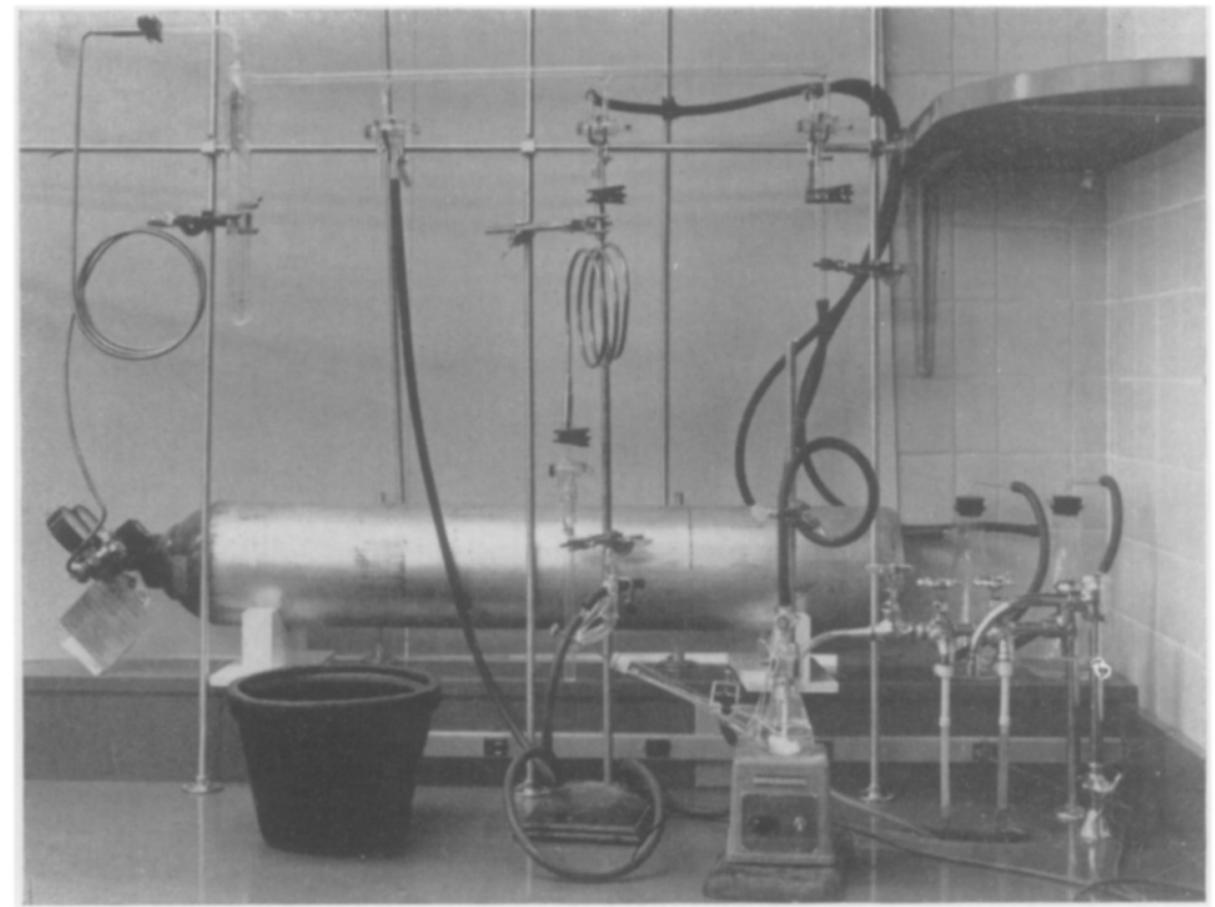

FIG. 4. Photograph of arrangement of various components on the bench.

standard taper female joint (as shown in Fig. 1) using epoxy cement. The syringe is attached to the flask, filled with titrant, and transferred to the cuvet unit. Before inserting the syringe into the flask, the magnetic stirrer is turned on for a few moments to mix the dithionite solution. The exit tube of the gas lock (sce Fig. 2) is then clamped off and the cap removed from the $\mathbf{7 / 2 5}$ standard taper male joint, allowing the gas to rush through the opening of the joint. After carefully regrcasing the malc joint, the needle is inserted through the rubber septum into the flask and the syringe seated firmly on the joint. The exit tube from the gas lock is then reopened to provide continuous sweeping oi the oxygen-frce gas over the rubber septum. The syringe is filled and emptied several times in this position to remove residual air. The solution is then stirred and the syringe filled with the titrant to a slight excess of the amount requircd for titration.

(5) The filled syringe is then transferred to its working position on the cuvet in the following manner: The exit tube from the gas lock on the cuvet is closed off and the cap of the $7 / 25$ standard taper male joint removed. This joint is then carefully regreased. The filled syringe is then carefully removed from its position on the titrant flask (and replaced by the eap) and its needle inserted into the opening in the male 
joint of the cuvet with the point held just above the rubber septum while 2-3 drops of the titrant (which may have been exposed to oxygen) is expelled onto the top of the septum. The needle is then thrust quickly through the septum and the syringe seated firmly onto the male joint. The exit tube of the gas lock is then reopened to allow gas flow. An important feature of the unit is that the tip of the needle rests in the groove of the cuvet side arm when the syringe is seated, thus ensuring even mixing of titrant drops with a minimum of tipping for each measurement (see Fig. 1).

(6) The cuvet gas lock is now clamped off and the cuvet unit is transferred to the spectrophotometer, where the titration proceeds. Volume of additions may be measured by either reading the syringe as a buret or calibrating the screw and counting the turns of the additions. In these experiments both methods were used as an internal check on the data. After an initial buret reading and spectrum are taken, the first addition is made and the cuvet tipped several times to ensure complete mixing of the titrant. The $\mathrm{OD}_{443}$ is then read from the spectrophotometer (or, alternatively, a complete spectrum taken) and the buret again read. Turns of the threaded plunger were also recorded. Adequacy of the tipping procedure to mix the titrant was tested by doing a preliminary experiment with water in the cuvet and a colored dye in the syringe. The titration is completed by repeating the above steps for every point taken. In the final calculations, the values were corrected for volume change when the titrant was added.

\section{RESULTS}

The results shown in Table 1 are from dithionite titrations of lumiflavin acetic acid using the same dithionite solution, which was made up on the first day, and the titrant flask left intact for the following two experiments which were done on consecutive days. The cuvet unit was disassembled and thoroughly cleaned between each of the measurements. The exact amount of lumiflavin acetic acid in each experiment was calculated from the volume in the cuvet and the initial $\mathrm{OD}_{443}$ using an extinction coefficient of $11.5 \mathrm{~m} M^{-1} \mathrm{~cm}^{-1}$ for the oxidized form, or alternatively an extinction coefficient for the oxidized minus reducea

TABLE 1

\begin{tabular}{cccc}
\hline Experiment & $\begin{array}{c}\text { Lumiflavin acetic acid, } \\
\mu \text { moles }\end{array}$ & $\begin{array}{c}\text { Dithionite soln., } \\
\text { ml }\end{array}$ & $\begin{array}{c}\text { Conen, of dithionite } \\
\text { soln., calcd. } \\
\text { m } M\end{array}$ \\
\hline 1 & 0.496 & 0.360 & 1.38 \\
2 & 0.397 & 0.278 & 1.43 \\
3 & 0.396 & 0.280 & 1.42 \\
\hline
\end{tabular}




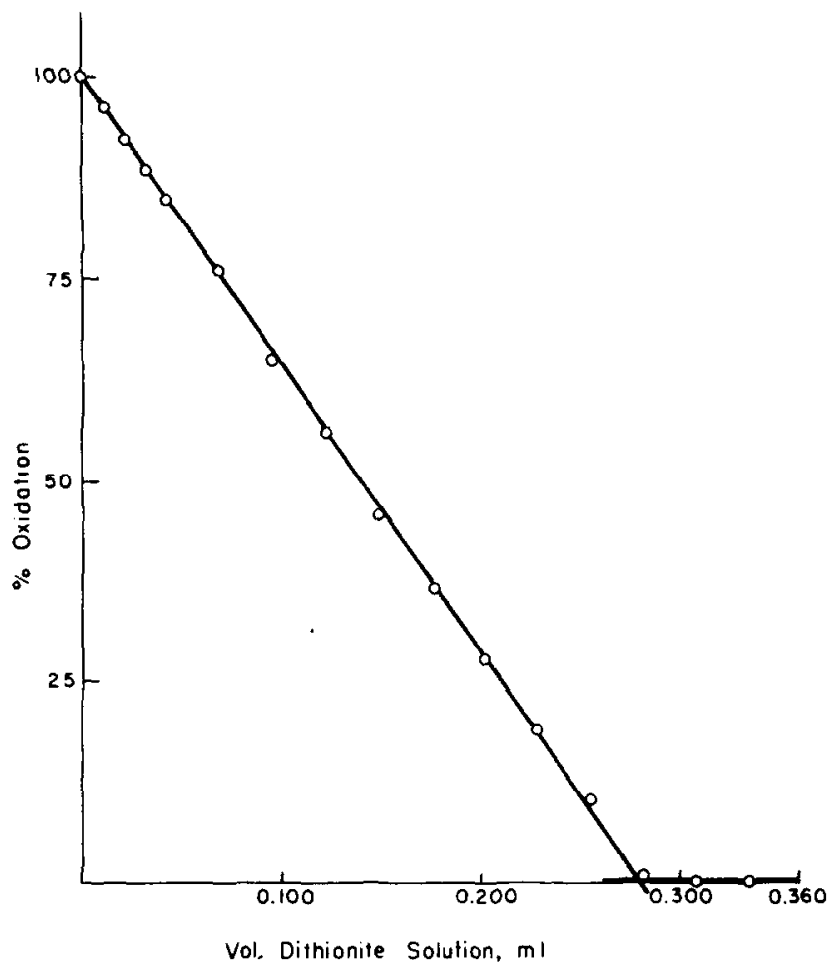

Fra. 5. Typical titration aurve.

absorption of $10.8 \mathrm{mM}^{-1} \mathrm{~cm}^{-1}$ (3). Both calculations gave essentially the same value. A typical titration curve is shown in Figure 5. The curve is for experiment 2 in Table 1 and it is seen that the precise volume of dithionite solution necessary for full redurtion of the lumiflavin, 0.278 $\mathrm{ml}$, is found by extrapolation from the linear portions of the curve before and after the fully reduced state is reached. The average value for the concentration of the dithionite solution from the measurements over 3 days is $1.41 \mathrm{~m} M$ and the consistency of the three measurements indicates that the dithionite solution is relatively stable under these conditions for at least that period of time. The precise end points obtainable with lumiflavin acetic acid titrations should therefore provide a useful means of determining the strength of dithionite solutions which are subsequently employed to titrate other redox systems, such as the redox enzymes, using this method. Such studies are presently in progress in our laboratory with the flavin containing Escherichia coli enzymes dihydrolipoamide dehydrogenase, glutathione reductase, and thioredoxin reductase. 


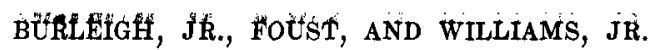

\section{REFERENCES}

1. Massey, V., Gibson, Q. H., and Veeger, C., Biochem. J. 77, 341 (1960).

2. Foust, G. P., Burleigh, B. D., Jr., Mayhew, S., Williams, C. H., Jr., and Massey, V., Anal. Biochem., this issue.

3. Massey, V., personal communication. 